\title{
Immunoproteomic analysis of Clostridium botulinum type B secretome for identification of immunogenic proteins against botulism
}

\author{
Arti Sharma $(\mathbb{D} \cdot$ S. Ponmariappan $\cdot$ Sarita Rani $\cdot$ S. I. Alam $\cdot$ S. Shukla
}

Received: 6 March 2020/Accepted: 1 February 2021/Published online: 25 February 2021

(C) The Author(s), under exclusive licence to Springer Nature B.V. part of Springer Nature 2021

\begin{abstract}
Objectives To identify immunogenic proteins of $C$. botulinum type $\mathrm{B}$ secretome by immunoproteomic analysis.

Results In the present study, an attempt was made to elucidate the vaccine candidates/diagnostic molecules against botulism using immuno proteomic approach. C. botulinum type B secretome was elucidated when it was grown in TPGY as well as CMM media. Predominant 51 proteins were identified in both the media using 2-DE and mass spectrometry analysis. 2D gels (CMM \& TPGY) were probed with respected proteins mice antiserum and obtained 17 and 10 immunogenic proteins in TPGY as well as CMM media respectively. Hypothetical protein CLOSPO_00563, ornithine carbamoyl transferase,
\end{abstract}

Supplementary Information The online version contains supplementary material available at https://doi.org/10.1007/ s10529-021-03091-4.

A. Sharma $(\bowtie)$

Government Degree College, Prithvipur District,

Niwari 472336, India

e-mail: arti.biochem05@gmail.com

A. Sharma - S. Ponmariappan - S. Rani - S. I. Alam Biotechnology Division, Defence Research \&

Development Establishment, Gwalior 474 002, India

A. Sharma $\cdot$ S. Shukla

Zoology Department, Jiwaji University, Gwalior,

Madhya Pradesh, India
FlaA, molecular chaperone GroEL and secreted protease proteins were found as the common immuno dominant proteins in both media. Polyclonal Antibodies raised against $C$. botulinum types $\mathrm{A}$ and $\mathrm{E}$ showed cross-reactivity with secretome $C$. botulinum type B at the lowest dilution $(1: 1000)$ but did not show cross reactivity with highest dilution $(1: 30,000)$ with $C$. botulinum type B secretome. Polyclonal antibodies against $C$. botulinum type $\mathrm{F}$ secretome did not show cross reactivity with $C$. botulinum type B secretome. Conclusions Identified immunogenic proteins can be used as vaccine candidates and diagnostic markers for the infant and wound botulism but common immunogenic proteins may be the best vaccine candidate molecule for development of vaccine as well as diagnostic system against the infant and wound botulism.

Keywords Immunoproteomics - Clostridium botulinum type B · Neuroparalytic disease . Anaerobes · Botulism

\section{Introduction}

Clostridium botulinum is a Gram positive, obligate anaerobic and endospore forming bacterium that produces botulinum neurotoxins (Maikanov et al. 2019). It is the most potent neurotoxin so far known to 
humans hence it is categorized as a bio-warfare category ' $A$ ' agent. It has been divided into seven serotypes designated (A-G) which have similar structure but differ antigenically. Generally, serotypes A, B, E are associated with human clinical cases but rarely serotype F. Among the seven serotypes, A and B are the most poisonous serotypes. It causes neuroparalytic disease in humans and in animals called botulism (Lanci et al. 2019). There are three types of botulism; infant botulism, wound botulism and food borne botulism. Infant botulism is caused by swallowing of botulinum spores present in the environment. These spores are converted into vegetative cells followed by germination which then multiply and colonize in the large intestine leading to secretion of botulinum neurotoxin (BoNT) in situ (Galvis 2019). Similarly when the wounds are exposed to the environment, the $C$. botulinum spores enter into the wound followed by multiplication of the bacteria and produce the toxin. The toxin gets absorbed into the bloodstream and causes the wound botulism (Kuehn 2019). Both infant and wound botulism are caused by primary infection followed by secondary intoxication. But food borne botulism is caused by the intake of preformed BoNT containing food (Forss et al. 2012; Palma et al. 2019). The neurotoxin is absorbed and carried by the bloodstream to neuromuscular junctions where it blocks the release of acetylcholine and causes flaccid paralysis. So far there is no licensed vaccine commercially available for botulism. Similarly there is no rapid detection system available to diagnose botulism. The Centre for Disease Control and Prevention (CDC) used to provide the pentavalent toxoid as an investigational vaccine for select risk groups but it has been discontinued since 2011 due to the decrease in the antibody titer of certain serotypes as well as increasing side effects after the booster (Notice of CDC's discontinuation of investigational pentavalent (ABCDE) botulinum toxoid vaccine for workers at risk for occupational exposure to botulinum toxins 2011). Several studies have been attempted for the development of recombinant protein based subunit vaccine using different domains of the heavy chain of different serotype (Przedpelski et al. 2018). Few studies have been directed towards the use of DNA based vaccines for different serotypes (Kim et al. 2019). Both the studies have revealed that, the binding domains are immunogenic and provide neutralization against the toxins but the risk of using the full domain of the toxin, reactivity of the recombinant proteins with other human proteins and other ethical concerns using the active toxin part for immunization. Immuno proteomic approach is one of the best tools available to study the host-pathogen interactions (McClean 2012). Researchers used combination of 2DE and immuno blotting with sera from infected animals and mass spectrometry to find out the immunogenic candidates (Pedersen et al. 2005). Similar approach has been widely used for the discovery of new biomarkers for vaccine development in cancer as well as infectious diseases (Forgber 2009; Martinez-Lopez 2008; Mendum 2009; Pitarch et al. 2006; Pitarch and Gil 2011). The secretory proteins play important roles in the pathogenesis of bacterial infection, represent the interphase of the bacterium-host interaction (Tsai-Tien Tseng 2009). In any pathogens the secretory proteins are exposed to the host immune system and are therefore the primary antigen targets of host immune response (Fulton and Twine 2013). Numerous novel secretory proteins produced by different bacteria such as Helicobacter pylori (Bernardini et al. 2007), Pseudomonas aeruginosa (Nouwens 2002) and Staphylococcus aureus (Ziebandt 2001) have been identified in secretome by using two-dimensional gel electrophoresis and mass spectrometry approach to develop the vaccine candidates as well as diagnostic system. Moreover the secretory immunogenic molecules are important for the development of diagnostics and passive immunotherapy (Vanitha Mariappan 2009). Identification of the secretory immunogenic proteins would be further step towards understanding the humoral immune response during $C$. botulinum infection. The aim of the present study was to identify and characterize immunogenic proteins from $C$. botulinum type $\mathrm{B}$ secretome by a combination of 2DE and immunoblotting assay using antisera raised in mice against the secretory proteins. Some of these immunogenic proteins have potential to be used as novel vaccine candidates or may be useful for enhancing the protective efficacy of a protectiveantigen-based vaccine. However, information regarding the secretome profile as well as immunogenic proteins of $C$. botulinum is not available in literature. The novel immunogenic proteins may be developed as alternative antigens for further study of botulism vaccine and diagnostics. 


\section{Materials and methods}

Bacterial strains, growth and culture condition

Indian isolates of $C$. botulinum type A SP08 (DRDE Accession No. DB120CLBO8), type B isolate SP11 (DB123CLB11), type E isolate SP01 (DB113CLBO1) and type F isolate SP04 (DB116CLBO4) were retrieved from the DRDE repository and further confirmed by polymerase chain reaction (PCR) using standard primers which were specific for BoNT/A, B, $\mathrm{E}$ and $\mathrm{F}$ (Lindstrom et al. 2001). Pure culture colonies were inoculated in serum vials containing $40 \mathrm{ml}$ presterilized, de-aerated TPGY and CMM media (Hi Media, India). TPGY media is being used for enrichment and CMM media for maintenance the $C$. botulinum type B culture. These cultures were incubated at $37{ }^{\circ} \mathrm{C}$ in an incubator shaker at $200 \mathrm{rpm}$ for 5 days.

\section{Preparation of extracellular proteins}

Cultures were centrifuged at $8000 \times g$ for $30 \mathrm{~min}$ at $4{ }^{\circ} \mathrm{C}$ and collected the supernatant then it was filtered through $0.22 \mu \mathrm{m}$ filters (Millipore, USA) to remove the suspended vegetative bacterial cells. Culture filtrates were concentrated using $10 \mathrm{kDa}$ cutoff membranes (Millipore, USA) and precipitated using 10\% Ice-cold trichloroacetic acid (Sigma USA) after that incubated on ice for $3 \mathrm{~h}$. Precipitate were centrifuged at $8000 \times g$ for $30 \mathrm{~min}$ at $4{ }^{\circ} \mathrm{C}$ and washed the pellet three times with cold acetone and left the room for air dried (Hirose et al. 2000). Further, the pellets were resuspended in protein solubilization buffer (8 M urea, 2\% CHAPS, and 2\% carrier ampholytes $\mathrm{pH} 4-7$ ) (Deatherage Kaiser et al. 2018). The resultant proteins were cleaned using protein clean up kit (Bio-Rad, USA). Protein concentration was estimated by Bradford method (SIGMA, USA) using Bovine serum albumin as a standard protein. Proteins was stored at $-80{ }^{\circ} \mathrm{C}$ for further use.

Two-dimensional gel electrophoresis

Secretary proteins $500 \mu \mathrm{g}$ was added into rehydration buffer (8 M urea, 4\% CHAPS, $0.002 \%$ bromophenol blue) and applied onto IPG strips (pH 4-7 and $\mathrm{pH} 4$ $0.7-5.9,11 \mathrm{~cm})$. Similarly, $300 \mu \mathrm{g}$ of protein was loaded onto the $7 \mathrm{~cm}$ IPG strips (pH 4-7 and 4.7-5.9).
Rehydration process was performed for $16 \mathrm{~h}$ at room temperature and isoelectric focusing (IEF system, BioRad, USA) procedure was carried out using following voltage profile: $200 \mathrm{~V}$ constant for $30 \mathrm{~min}$, a gradient from $2 \mathrm{~V}$ to $3500 \mathrm{~V}$ for $1.5 \mathrm{~h}$, and $3,500 \mathrm{~V}$ constant for $1 \mathrm{~h} 5 \mathrm{~min}$ (total, $6500 \mathrm{~V} / \mathrm{h}$ ) (Sharma et al. 2018). After focusing, IPG strips were equilibrated with DTT (50 mM Tris- $\mathrm{HCl}$ [pH 8.8], $6 \mathrm{M}$ urea, 30\% glycerol, $2 \%$ SDS and $0.002 \%$ bromophenol blue, $100 \mathrm{mg}$ DTT) and iodoacetamide (50 mM Tris- $\mathrm{HCl} \mathrm{[pH} \mathrm{8.8],}$ $6 \mathrm{M}$ urea, $30 \%$ glycerol, $2 \%$ SDS and $0.002 \%$ bromophenol blue, $250 \mathrm{mg}$ iodoacetamide) buffers. Strips were then transferred onto $12 \%$ SDS-PAGE for the second-dimension resolution. The gel was stained with Bio-Safe colloidal Coomassie Blue G-250 (BioRad, USA) and destained with autoclaved triple distill water and imaged using a GS-800 Densitometer (BioRad) employing PDQuest 7.1 software (BioRad).

\section{MALDI TOF-TOF analysis}

Protein spots were excised from 2D gels and washed thrice with proteomic-grade deionized water, destained followed by reduction/alkylation and finally the proteins were digested with trypsin using the Montage In-Gel digestion kit (Millipore, USA) as described by the manufacturer's. The digested protein $(0.8 \mu \mathrm{l})$ was mixed with $0.8 \mu \mathrm{l}$ of the matrix solution (5 mg $\alpha$-cyano-4-hydroxycinnamic acid in $80 \%$ acetonitrile and $0.1 \%$ trifluoroacetic acid [TFA]) thoroughly by pipetting for spectral scanning. This mixture $(1 \mu \mathrm{l})$ was deposited onto the MALDI plate and proteins were identified by mass spectrometry (MS) using a matrix-assisted laser desorption ionization-tandem time-of-flight (MALDI-TOF-TOF) mass spectrometer (Ultraflex III; Bruker Daltonics, Germany). MS mass spectra had been noted in the reflector positive mode using a laser (wavelength $355 \mathrm{~nm}$ ) operated at a $200 \mathrm{~Hz}$ recurrence rate and at $2 \mathrm{kV}$ accelerated voltage. The MS/MS mass spectra had been developed using data dependent acquisition method. In this method, 20 strongest precursors selected between 850 and $4000 \mathrm{Da}$ and filtered through a signal-to-noise ratio more than 20 from one MS scan. Precursor ions had been selected by timed ion selector (TIS). Fragmentation had been done through collision induced dissociation (CID) method by air (collision gas) at $1 \mathrm{kV}$ energy as well as recharge pressure threshold of $1.5 \mathrm{e}-006$. MS and MS- 
MS spectra were obtained by accumulation of at least 1200 and 1600 laser shots, respectively. MS and MS/ MS data were analyzed and peak list were generated using the 4000 Series Explorer Software v. 3.5 (Applied Biosystem, USA). A peak intensity filter was used with no more than 50 peaks per $200 \mathrm{Da}$ in the setting parameter of MASCOT search after acquisition. MS/MS peaks were selected based on a signal-tonoise ratio greater than 10 over a mass range of 60-20 Da below the precursor mass. MS and MS/MS data had been analyzed using Protein Pilot version 4.0 (Applied Biosystem) the MASCOT 2.0 search engine (Matrix Science, London). The peak list had been examined against 3,239,079 entries for Firmicutes at non-redundant protein sequence database of NCBI. Trypsin digestion with one missed cleavage, oxidation of methionine, carbamidomethylation of cystein and the peptide mass tolerance of $50 \mathrm{ppm}$ for precursor ion and mass tolerance of $\pm 0.6 \mathrm{Da}$ for fragment ion with +1 charge state were search parameters. MS/ MS was successfully identified proteins, MASCOT score more than 60 was accepted as significant $(p$ value $<0.05)$.

\section{Bioinformatics analysis}

Proteins function had been predicted by UniProt Knowledge base (Swiss-Prot and TrEMBL). Signal peptide had been predicted by Signal $\mathrm{P}$ software in Gram-positive bacteria. (network http://www.cbs.dtu. $\mathrm{dk} /$ services/SignalP). Transmembrane helices numbers had been explored by TMHMM 2.0 (http://www. cbs.dtu.dk/services/TMHMM/). Prediction of lipoproteins and signal peptides had been analyzed by Lipo P 1.0 (http://www.cbs.dtu.dk/services/LipoP/). Grand average of hydropathy had been calculated by gravy calculator (http://www.gravy-calculator.de/). Sub-cellular localization of protein had been predicted by PSORT b version 2.0 (http://www.psort.org/ psortb2.

Immunization and generation of polyclonal antibody

The Animal experiments had been approved by the Institutional Animal Ethical Committee (IAEC) of the Defence Research \& Development Establishment (DRDE), Gwalior, India. Polyclonal antibodies had been generated in $\mathrm{BALB} / \mathrm{c}$ female mice via intra- peritoneal route against secretory proteins of $C$. botulinum type $\mathrm{B}$, which were expressed in TPGY and CMM media. Active immunization $(0,14,21$, 28 days) schedule had been performed using $10 \mu \mathrm{g}$ protein with complete Freund's adjuvant followed by three booster doses of 20,30,50 $\mu \mathrm{g}$ protein with incomplete Freund's adjuvant. Similarly polyclonal antibodies had been generated against $C$. botulinum type $\mathrm{A} / \mathrm{E}$ and $\mathrm{F}$.

\section{Indirect ELISA}

Indirect Enzyme-linked immunosorbent assay (ELISA) was performed to check the antibodies titre in mice against extracellular proteins of $C$. botulinum type B. Briefly, the 96 well ELISA plates were coated with $5 \mu \mathrm{g} / \mathrm{ml}$ extracellular proteins (CMM and TPGY medium) and incubated the plates overnight at $4{ }^{\circ} \mathrm{C}$. Then plate was washed three times with PBST $\left(137 \mathrm{mM} \mathrm{NaCl}, 2.7 \mathrm{mM} \mathrm{KCl}, 4.3 \mathrm{mM} \mathrm{Na} \mathrm{HPO}_{4}\right.$, $1.47 \mathrm{mM} \mathrm{KH} \mathrm{PO}_{4}$ and $0.05 \%$ Tween-20, $\mathrm{pH} 7.4$ ) followed by three times washing with phosphate buffer saline (PBS). Plates were blocked with 3\% bovine serum albumin (BSA) at $37{ }^{\circ} \mathrm{C}$ for $1 \mathrm{~h}$. Plates were washed as mentioned previously followed by addition of $100 \mu \mathrm{l}$ per well, two fold diluted primary antibody from 1:1000 to 20, 48,000 (mice sera against extracellular proteins expressed in TPGY and CMM media). Similarly the preimmunized serum incubated at $37{ }^{\circ} \mathrm{C}$ for $1 \mathrm{~h}$. Then plate was washed three times with PBST and three times with PBS. After washing, $100 \mu \mathrm{l}$ per well of secondary antibody rabbit antimouse IgG-HRP (Dako, Denmark) 1:2000 dilution was added and incubated at $37^{\circ} \mathrm{C}$ for $1 \mathrm{~h}$. Then the plate was washed as described previously. Finally the antigen and antibody interactions was developed using 2,2'-azino-bis (3-ethylbenzo-thiazoline-6-sulphonic acid) diammonium salt solution $(100 \mu \mathrm{l} /$ well $)$ containing $\mathrm{H}_{2} \mathrm{O}_{2}$ and incubated at $37{ }^{\circ} \mathrm{C}$ for $30 \mathrm{~min}$. Absorbance was measured at $410 \mathrm{~nm}$ using an ELISA plate reader (Biotek, USA). Similarly ELISA assay was done for secretory proteins antiserum against $C$. botulinum type $\mathrm{A} / \mathrm{E}$ and $\mathrm{F}$.

Western blot analysis

2-DE gels were transferred onto PVDF membrane in semi-dry condition using transfer apparatus (Bio-Rad, USA) at $100 \mathrm{~V}$ for $1 \mathrm{~h}$ at $4{ }^{\circ} \mathrm{C}$ in tris glycine transfer 
buffer $(25 \mathrm{mM}$ Tris, $192 \mathrm{mM}$ glycine and $10 \%$ methanol). The membranes were blocked with $5 \%$ skimmed milk and incubated at $4{ }^{\circ} \mathrm{C}$ overnight. Further membranes were washed three times with PBST followed by PBS twice with 10 min interval. Membranes were probed with polyclonal antibodies (1:30,000 dilutions) generated in mice against the extracellular proteins expressed in TYGY and CMM media. Unimmunized mice serum (1:1000) was used as negative control for immunoblotting. The membranes were washed as washed previously and incubated for $1 \mathrm{~h}$ with 1:30,000 dilution Anti-Mouse IgG (Fc specific)-Peroxidase antibody. After washing with PBST, the membrane was developed by DAB substrate (SIGMA, USA). Similarly 2D-gel of type B secretory proteins were probed with other $C$. botulinum types A, E, F secretory proteins anti serum at dilutions of $1: 30,000$ and $1: 1000$.

\section{Results and discussion}

Identification of predominantly expressed protein spots in TPGY and CMM media

Proteomics has been become a technique for identification of proteins involved during infection and invasion by the pathogens (Das et al. 2019). Bacterial secreted proteins perform key role in the interaction between the bacterial cell and the host environment (Siegrist et al. 2015). Thus secretome of a pathogen are hypothesized to comprise the components of effective vaccines. Secretome exploration facilitates identification of novel vaccine antigen and overall helps in progress of discovery of vaccine (McManus 2020). In the present work, predominantly expressed protein spots were successfully identified by mass spectrometry. Most of the proteins were over expressed in TPGY medium compared to CMM medium. The list of predominantly expressed proteins in both TPGY and CMM media are being shown in Fig. 1 and tabulated in Table 1. Glyceraldehyde-3-phosphate dehydrogenase, type I, chlorohydrolase/aminohydrolase, molecular chaperone GroEL, hypothetical protein CLOSPO_00563, dehydrogenase, FMNdependent, trios phosphate isomerase, E-cinnamoylCoA:R-phenyl lactate CoA transferase large subunit, thiamine biosynthesis protein $\mathrm{ThiC}$, amino peptidase 1, putative cell surface protein, acetyl-CoA acetyltransferase, carbamate kinase, secreted protease, clostripain, molecular chaperone DnaK, enolase, ornithine carbamoyltransferase, butyrate kinase, aspartate/ornithine carbamoyltransferase family protein, thermolysin metallopeptidase, glycosyl

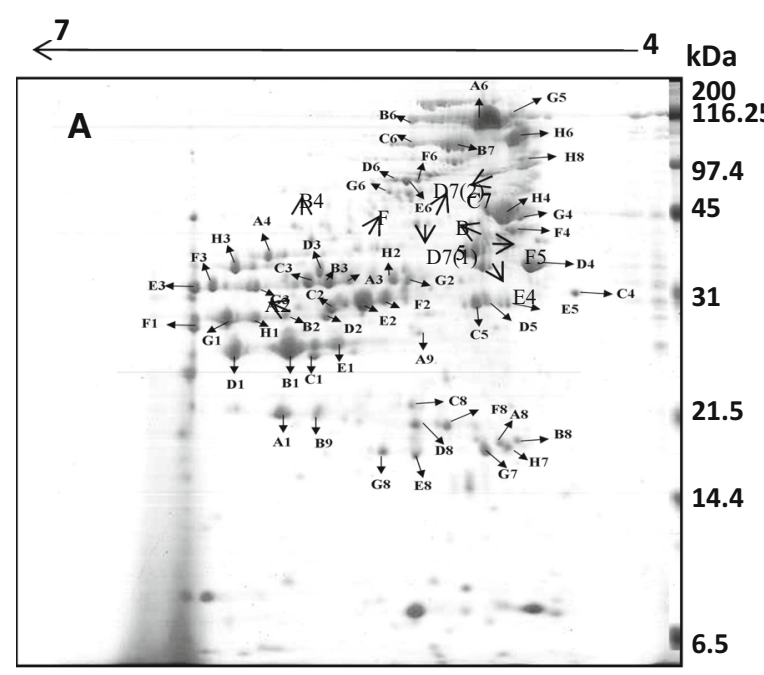

Fig. 1 Two-dimensional map of Bio-Safe Coomassie G-250stained gel of secretome proteins of C. botulinum type B Indian isolate SP11 grown in TPGY (a) and CMM medium (b). Proteins were separated in the first dimension by a $\mathrm{pH} 4$ to 7 immobilized $\mathrm{pH}$ gradient gel (length, $11 \mathrm{~cm}$ ) and then in the

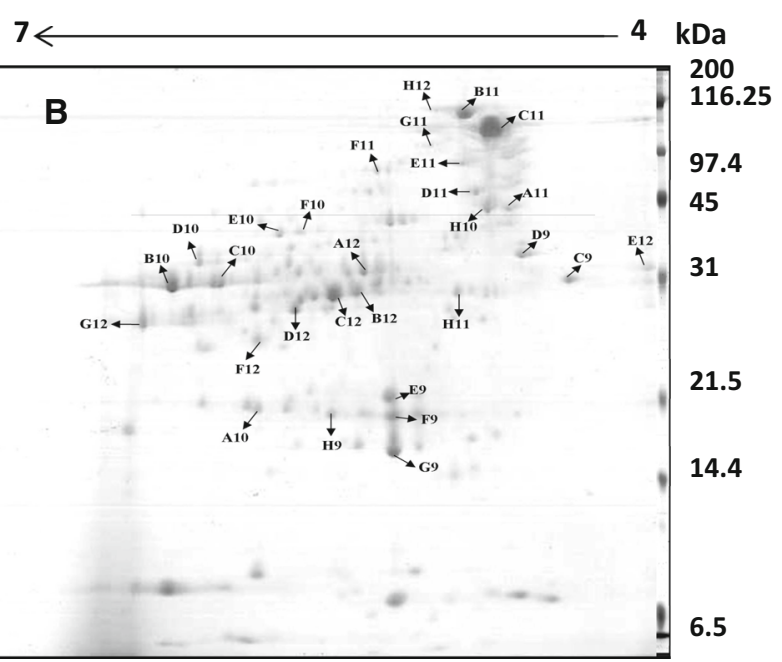

second dimension by a $12 \%$ SDS-PAGE. The positions of molecular weight standards are indicated on the right. Protein spots were identified by MALDI-TOF-MS and database searches are indicated by the spot numbers given in Table 1 


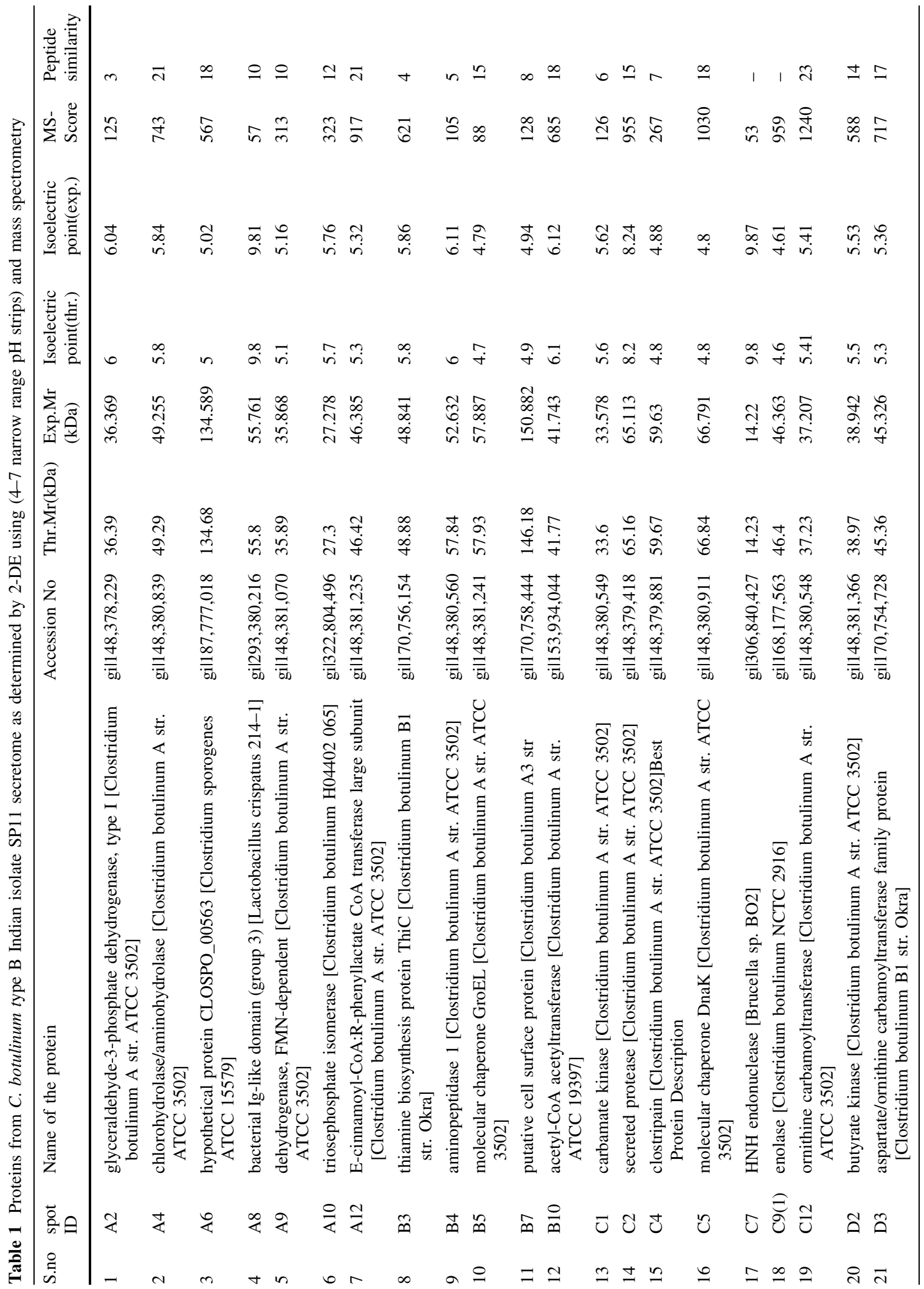




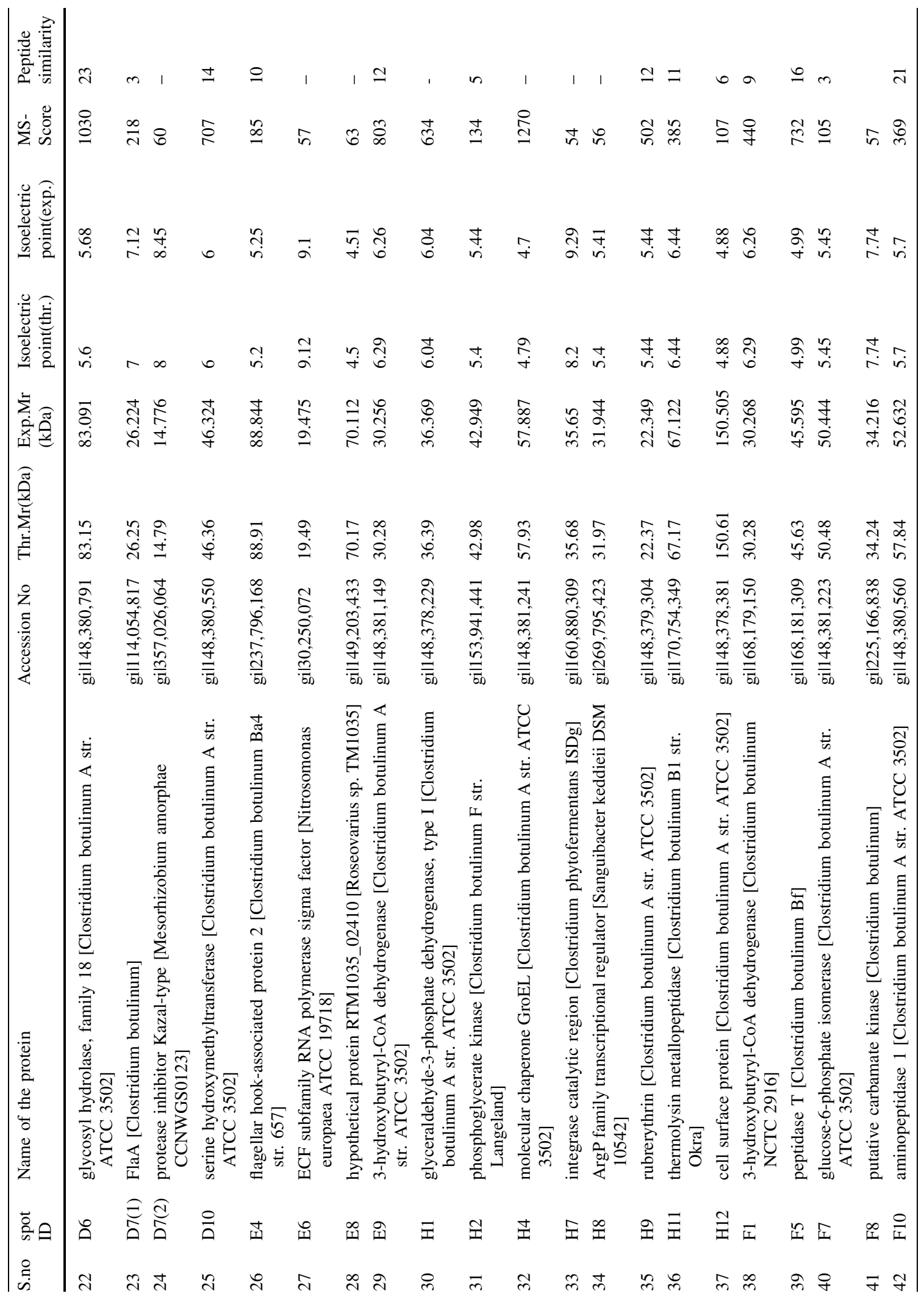




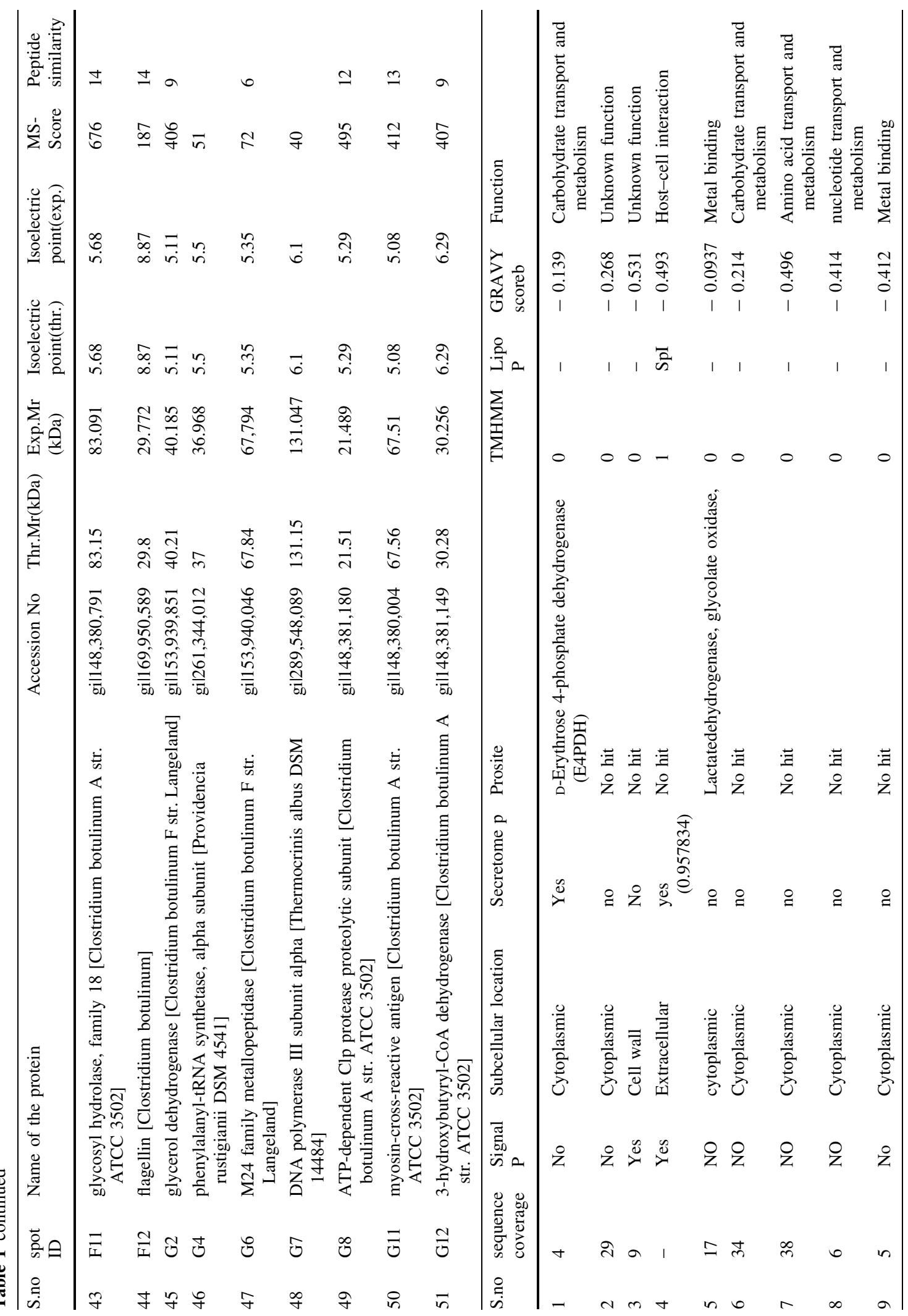




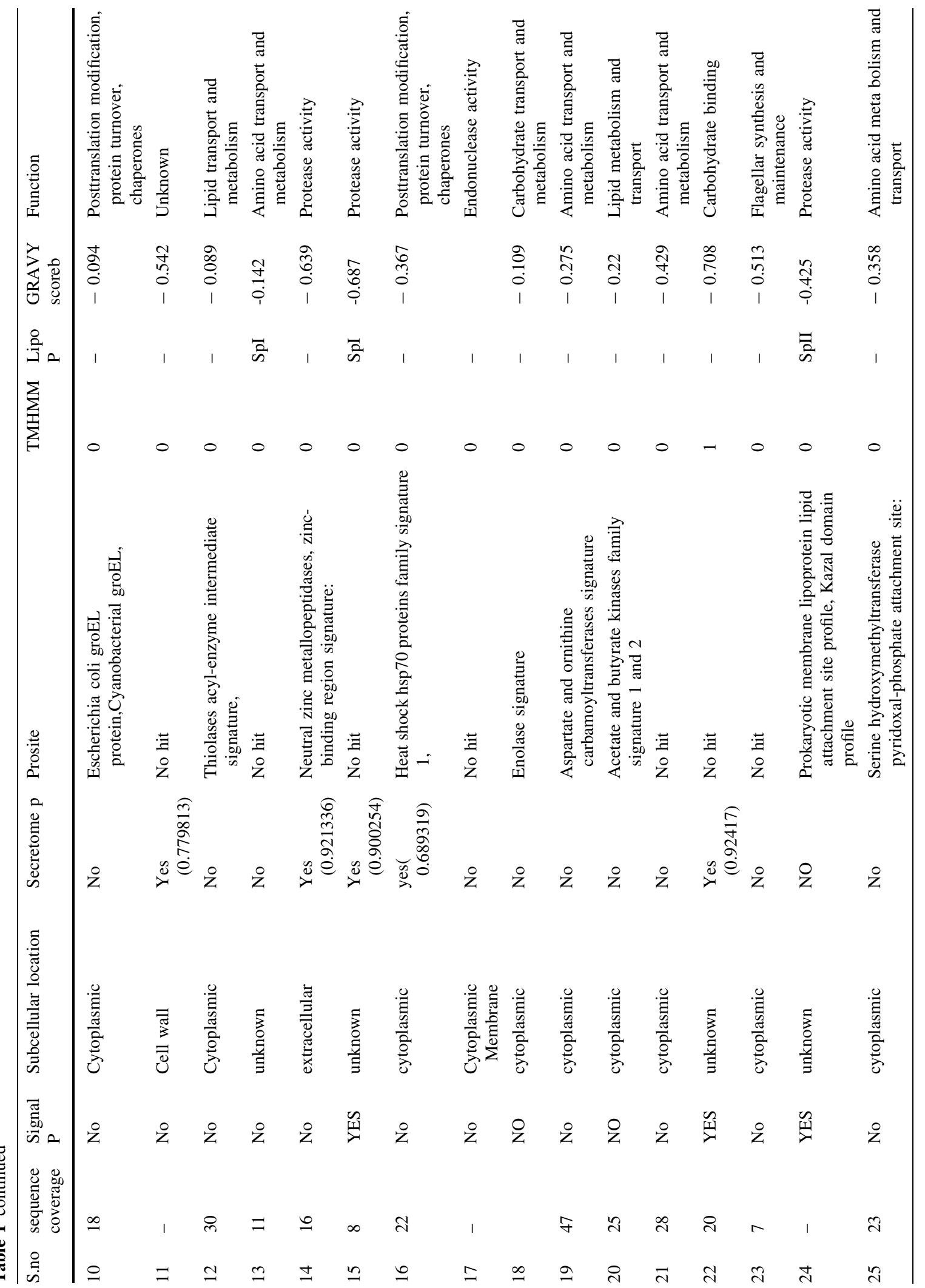




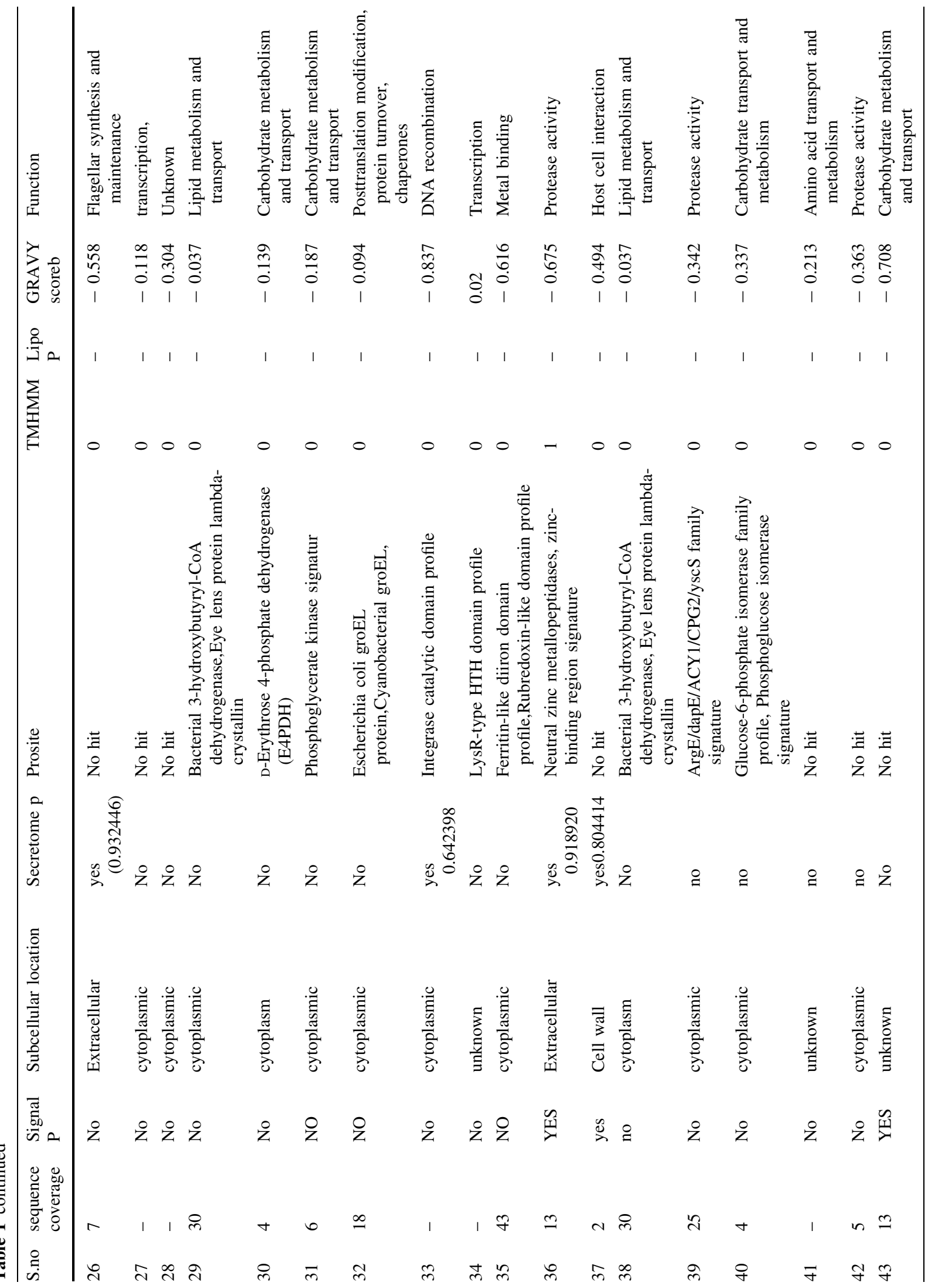




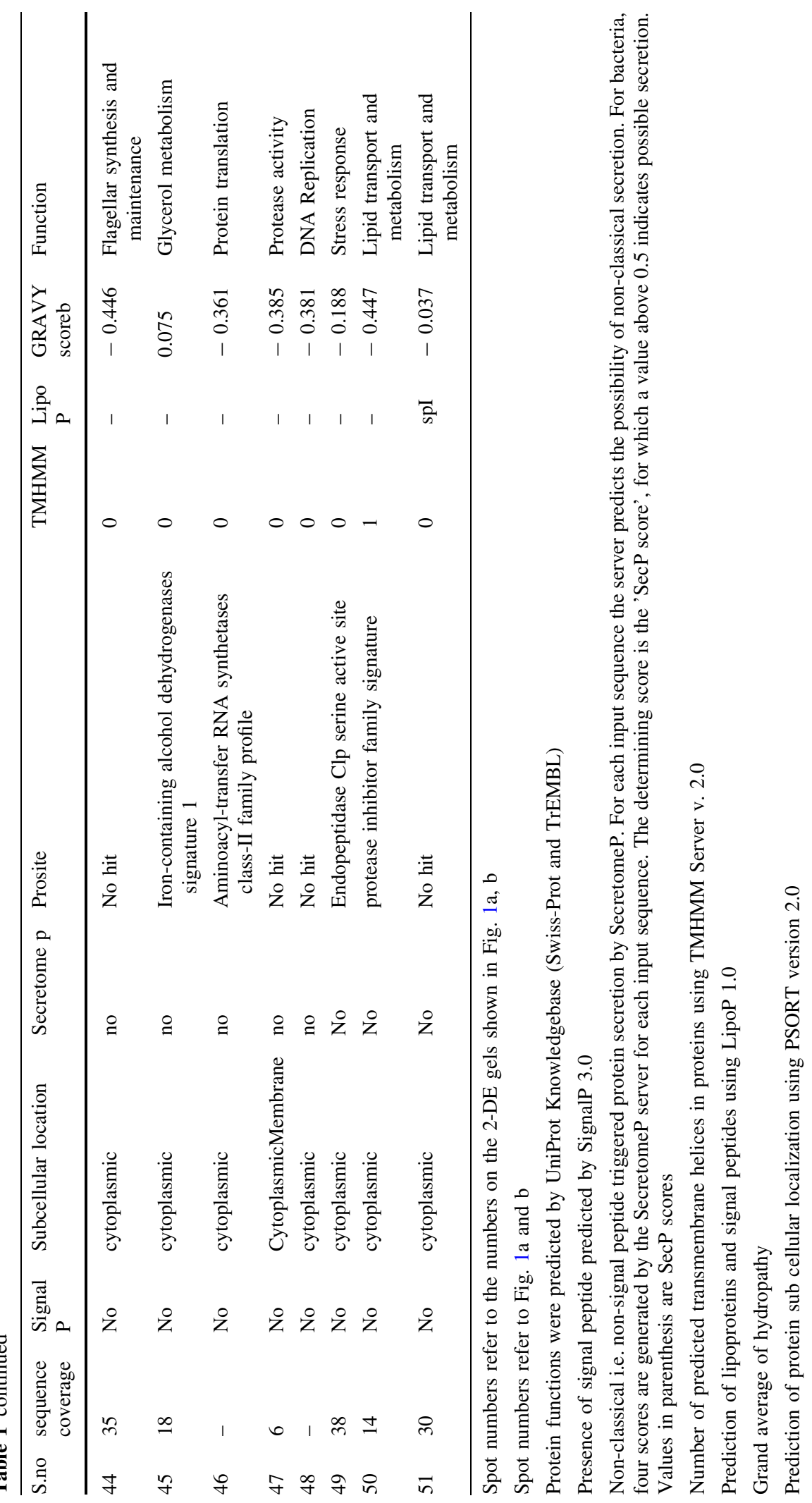


hydrolase, family 18, ATP-dependent Clp protease proteolytic subunit, flagellin and M24 family metallopeptidase were predominant proteins. Elevated levels of these proteins had been also seen in $C$. tyrobutyricum secretome (Ma et al. 2015). Clostripain (Shimizu et al. 2002), ThiC (Martinez-Gomez and Downs 2008), peptidaseT (Strauch et al. 1983), Glycerol dehydrogenase (Monniot et al. 2012), glyceraldehyde-3-phosphate dehydrogenase and acetylCoA acetyltransferase (Prasad et al. 2013; Sengupta et al. 2010) predominant proteins had been also identified by other researchers in other microorganism using proteomic approach.

Bioinformatics analysis

Clostridium botulinum type B secretary proteins were grouped into different cellular functions and shown in Fig. 2. Identified secretary proteins are involved in carbohydrate $13.7 \%$, amino acid and lipid $11.76 \%$ metabolism, protease activity (13.7\%), metal binding, posttranslational modifications, flagellar synthesis and maintenance $(5.88 \%)$, host cell interaction and transcription process $(3.9 \%)$, protein translation, carbohydrate binding, endonuclease activity, stress response, DNA replication and recombination $(1.9 \%)$ and unknown function (7.8\%). Similar trends were also observed in $B$. anthracis secretome in which $17.8 \%$ proteins are involved in energy metabolism, $10.9 \%$ for protein synthesis, $8.7 \%$ cellular structure and $13 \%$ proteins functions are unknown (Walz et al. 2007). Hypothetical protein CLOSPO_00563, putative cell surface protein and cell surface protein were predicted as cell wall-associated protein, bacterial Iglike domain, secreted protease, flagellar hook-associated protein 2 and thermolysin metallopeptidase were identified as extracellular proteins, HNH endonuclease and M24 family metallopeptidase found as cytoplasmic membrane proteins and 35-cytoplasmic proteins and 7-proteins of unknown localization were predicted using PSORTb software. Utmost of the $C$. botulinum type B secretome proteins were situated at

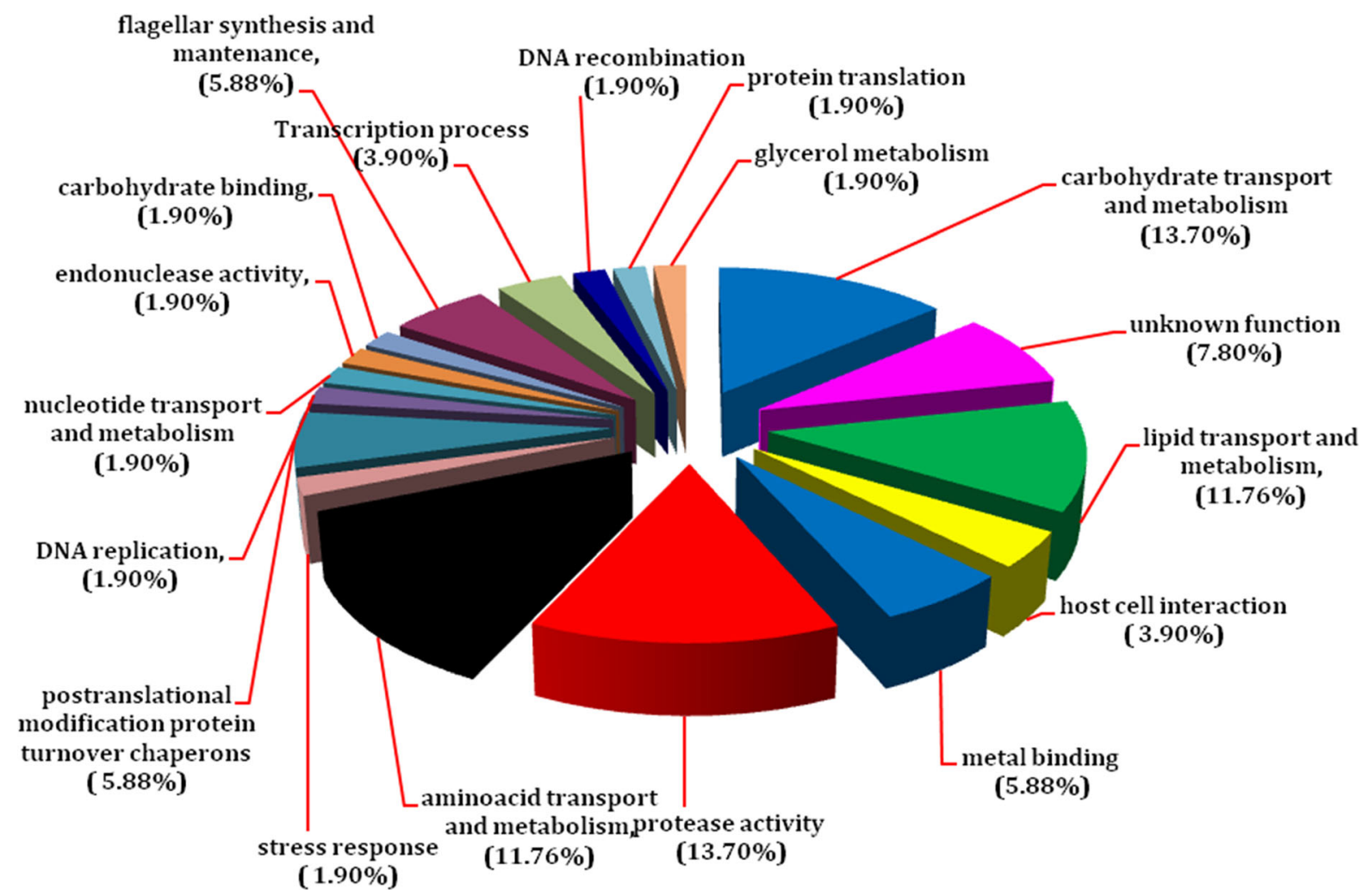

Fig. 2 Graphical representation of the cellular functions of secretome of $C$. botulinum type B Indian isolate SP11: the majority of the proteins were involved in transport and metabolism of carbohydrate, amino acid and lipid, protease activity, post-translational modification and chaperones 
the cytoplasmic region and did not contain signal sequence predicted by Signal P. Utmost of the enzymes involved in metabolism and energy production were present in the $C$. botulinum secretome. Similar results were also observed in Shigella flexneri (Liao et al. 2003). 15.68\% of proteins were predicted by Signal P to be secreted in the classical Sec pathway, which is characterized by the presence of a signal peptide (Shah et al. 2009). But, three proteins were shown to possess the cleavage site for signal peptidase I (SpI) and one protein for signal peptide II (SpII) are being shown in Table 1. Four proteins have transmembrane helices as predicted by TMHMM, representing an extra cytoplasmic but membraneassociated location. Less than $50 \%$ of the proteins were predictably secreted by either non-classical pathways as indicated by the presence of a signal peptide (Signal P) or non-signal peptide triggered protein secretion (Dwivedi et al. 2015).

\section{Immunogenic proteins of $C$. botulinum type B}

Immunoproteomics is an extension of proteomics, which permits specific elucidation of proteins based on immunoreactivity (Fulton et al. 2019). In procedure of immunoproteomics, 2-D gel blots are probed with antiserum collected from host post infection. This development has bypassed the extensive process of testing immunoreactivity and henceforth vastly enhanced the vaccine discovery by directly permitting the identification of those novel immunogenic proteins which evoke immune system. Secretary proteins of human disease causing agents are of special attention; in particular, these proteins play a role in the preliminary phase of pathogenesis when they arrive direct contact with host tissues (Kennedy 2018). If pathogenesis can be halted efficiently at the preliminary stage, infection can be paused. Secretary proteins can induce defensive immunity and also provoke an immune response which will be of specific attention for the development of vaccine/diagnostic markers. To determine the immunogenic proteins of C. botulinum secretome, antiserum of secretary proteins (1:30,000 dilution) were used as primary antibody and serum from unimmunized mice were used as control. Seventeen and ten immunogenic proteins were identified in TPGY and CMM media respectively, results are being shown in Figs. 3, 4 and tabulated in Tables 2, 3. Flagellin, secreted protease, hypothetical protein, ornithine carbamoyl transferase (OCT) and molecular chaperone GroEL were common immunogenic protein and are being tabulated in

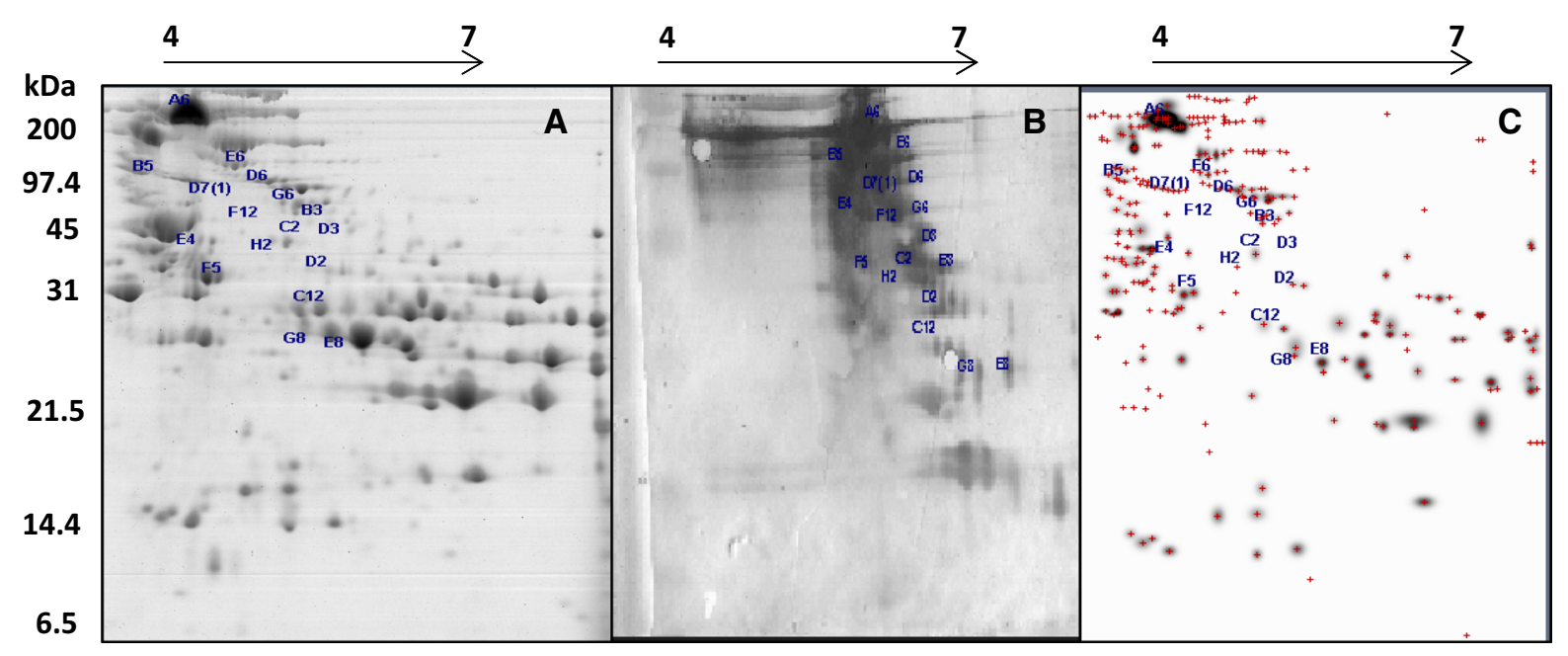

Fig. 3 Immunoblot analysis: antisera of secretory proteins (TPGY) $1 / 30,000$ dilutions binding to secretome proteins of C.botulinum type B Indian isolate SP11 grown in TPGY medium. Secretome of $C$. botulinum type $B$ were separated by 2-DE (pH 4-7, length $7 \mathrm{~cm}$ ) and stained with Bio-safe Coomassie G-250. a 2DE-map, b Western blot and c overlay image showed protein spots which were correspond in both
2-DE as well as immunoblot. The positions of molecular weight standards are indicated on the left. The immunoreactive protein spots were identified by MALDI-TOF-MS and database searches are indicated by the spot numbers given in Table 2 . Three technical replicates were organized in independent experiments; these were very similar, and one of them was revealed 


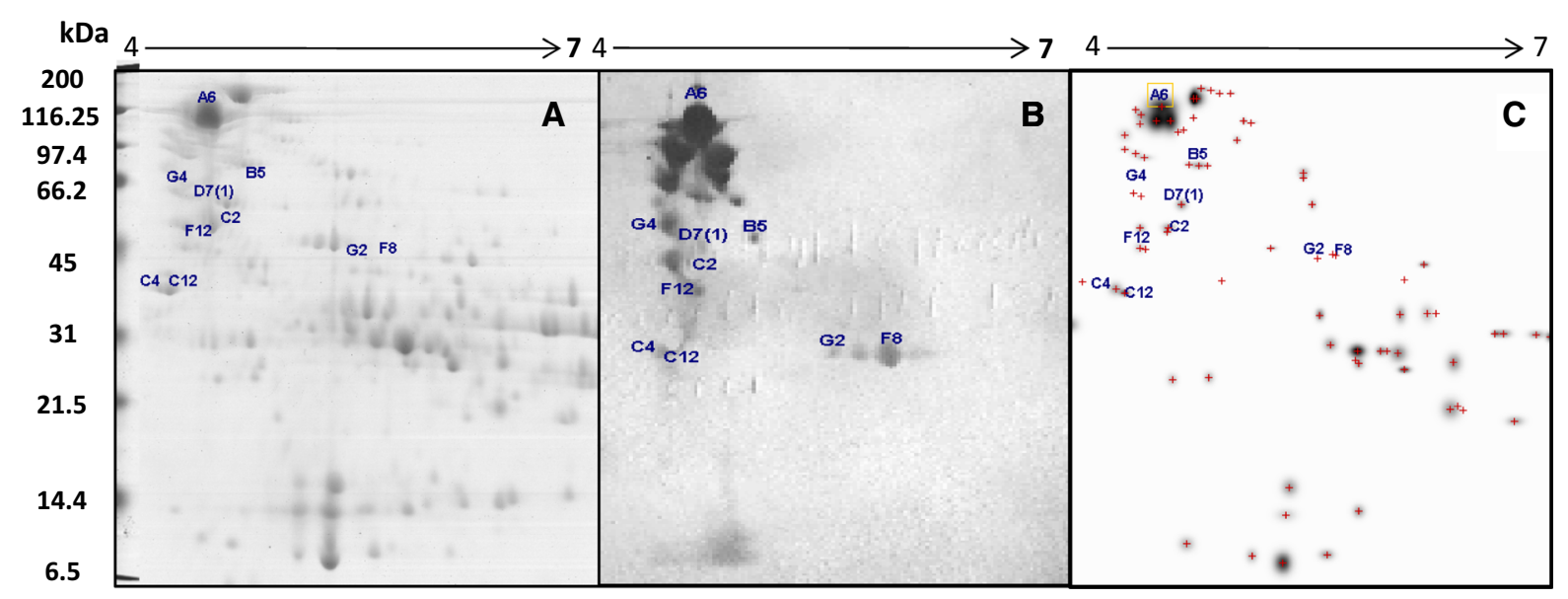

Fig. 4 Immunoblot analysis: antisera of secretory proteins (CMM) $1 / 30,000$ dilutions binding to secretome proteins of C.botulinum type B Indian isolate SP11 grown in CMM medium. Secretome of $C$. botulinum type $B$ were separated by 2-DE (pH 4-7, length $7 \mathrm{~cm}$ ) and stained with Bio-safe Coomassie G-250. a 2DE-map, b Western blot and c overlay image showed protein spots which were correspond in both

Table 2 Immunogenic proteins from $C$. botulinum type B Indian isolate SP11secretome grown in TPGY media as determined by 2-DE using (4-7 narrow range $\mathrm{pH}$ strips) and
2-DE as well as immunoblot. The positions of molecular weight standards are indicated on the left. The immunoreactive protein spots were identified by MALDI-TOF-MS and database searches are indicated by the spot numbers given in Table 3 . Three technical replicates were organized in independent experiments; these were very similar, and one of them was revealed

Mass spectrometry. Spot numbers refer to the numbers on the 2-DE western blot shown in Fig. 4

\begin{tabular}{ll}
\hline Spot ID & Extra-cellular Immunogenic proteins in TPGY media \\
\hline B3 & Thiamine biosynthesis protein ThiC [Clostridium botulinum B1 str. Okra] \\
A6 & Hypothetical protein CLOSPO_00563 [Clostridium sporogenes ATCC 15579] \\
D2 & Butyrate kinase [Clostridium botulinum A str. ATCC 3502] \\
D3 & Aspartate/ornithine carbamoyltransferase family protein [Clostridium botulinum B1 str. Okra] \\
D6 & Glycosyl hydrolase, family 18 [Clostridium botulinum A str. ATCC 3502 \\
C12 & Ornithine carbamoyltransferase [Clostridium botulinum B1 str. Okra] \\
E4 & Flagellar hook-associated protein 2 [Clostridium botulinum Ba4 str. 657] \\
E6 & ECF subfamily RNA polymerase sigma factor [Nitrosomonas europaea ATCC 19718] \\
E8 & Hypothetical protein RTM1035_02410 [Roseovarius sp. TM1035] \\
F5 & Peptidase T [Clostridium botulinum Bf] \\
G6 & M24 family metallopeptidase [Clostridium botulinum F str. Langeland] \\
G8 & ATP-dependent Clp protease proteolytic subunit [Clostridium botulinum A str. ATCC 3502 \\
H2 & Phosphoglycerate kinase [Clostridium botulinum F str. Langeland] \\
D7(1) & FlaA [Clostridium botulinum] \\
F12 & Flagellin [Clostridium botulinum A str. ATCC 3502] \\
C2 & Secreted protease [Clostridium botulinum A str. ATCC 3502] \\
B5 & Molecular chaperone GroEL [Clostridium botulinum A str. ATCC 3502] \\
\hline
\end{tabular}

Table 4. These proteins may be the best bioproducts for development of vaccine candidates or diagnostic markers against the infant and wound botulism. Cross reactive immunogenic proteins were also identified using secretary protein antisera of $C$. botulinum type $\mathrm{A} / \mathrm{E} \& \mathrm{~F}$ (supplement Fig. 1) and are being shown in 
Table 3 Immunogenic proteins from $C$. botulinum type B Indian isolate SP11secretome grown in CMM media as determined by 2-DE using (4-7 narrow range $\mathrm{pH}$ strips) and mass spectrometry

\begin{tabular}{ll}
\hline Serial no & Extra- cellular Immunogenic proteins in CMM medium \\
\hline A6 & Hypothetical protein CLOSPO_00563 [Clostridium sporogenes ATCC 15,579 \\
B5 & Molecular chaperone GroEL [Clostridium botulinum A str. ATCC 3502] \\
F8 & Putative cell surface protein [Clostridium botulinum A3 str. Loch Maree] \\
C4 & Clostripain [Clostridium botulinum A str. ATCC 3502]Best Protein Description \\
C12 & Ornithine carbamoyltransferase [Clostridium botulinum B1 str. Okra] \\
G2 & Glycerol dehydrogenase [Clostridium botulinum F str. Langeland \\
G4 & Phenylalanyl-tRNA synthetase, alpha subunit [Providencia rustigianii DSM 4541] \\
D7(1) & FlaA [Clostridium botulinum] \\
F12 & Flagellin [Clostridium botulinum A str. ATCC 3502] \\
C2 & Secreted protease [Clostridium botulinum A str. ATCC 3502] \\
\hline
\end{tabular}

Table 4 Common Immunogenic proteins from C.botulinum type B Indian isolate SP11 secretome grown in TPGY and CMM media

\begin{tabular}{ll}
\hline Serial no. & Extra- cellular Immunogenic proteins in TPGY and CMM media \\
\hline A6 & Hypothetical protein CLOSPO_00563 [Clostridium sporogenes ATCC 15579] \\
C12 & Ornithine carbamoyltransferase [Clostridium botulinum B1 str. Okra] \\
D7(1) & FlaA [Clostridium botulinum] \\
F12 & Flagellin [Clostridium botulinum A str. ATCC 3502] \\
C2 & secreted protease [Clostridium botulinum A str. ATCC 3502] \\
B5 & Molecular chaperone GroEL [Clostridium botulinum A str. ATCC 3502]
\end{tabular}

supplementary Figs. 2, 3 and tabulated in Tables 1 and 2. In $C$. difficile GroEL and DnaK were reported as immunogenic proteins and the recombinant GroEL immunized group decreases the intestinal colonization of $C$. difficile (Pechine et al. 2013). GroEL proteins had been also reported to be potent immunogens in a number of infections. Using immunoproteomics, GroEL of Neospora caninum has been identified to be immunogenic protein (Shin et al. 2004). Immunization with GroEL of Bacillus anthracis provides $100 \%$ protection against Bacillus anthracis infection in BALB/c mice (Sinha and Bhatnagar 2010). Merakou et al. showed that the flagellin protein enhancing immunity against $P$. aeruginosa. Antibodies against Flagellin protein were more potent in mediating opsonic killing of $P$. aeruginosa and mediating passive immunity in mice. This was attributed to flagellin inducing high titres of antibodies which could neutralise the innate immunity due to TLR5 activation (Merakou et al. 2018). Secreted protease play important roles in bacterial virulence during host infection, and have been previously proposed as potential vaccine candidates (Wang et al. 2019). OCT was previously suggested as a vaccine candidate to protect against both biofilm-related and acute Streptococcus suis infections (Wang et al. 2020). Whereas in the case of C. perfringens endo-beta-N-acetylglucosaminidase, SagA protein, phospholipase C, translation elongation factor, acetyl-CoA acetyltransferase, fructose-bisphosphate aldolase and ornithine carbamoyl transferase were reported as immunogenic proteins and the recombinant ornithine carbamoyl transferase extended the death time of mice challenged with $C$. perfringens (Sengupta et al. 2010). Phosphoglycerate kinase was successfully expressed by prokaryotic expression system and the recombinant protein showed favorable immunogenicity in mice (He et al. 2013) Peptidase protein had been known as immunogenic protein in anopheles culicifacies or gambiae for epitope design using immuno-informatics models (Jakhar et al. 2019). Metallopeptidase was identified as immunogenic proteins in various cancer 
including breast cancer (Chantada-Vázquez et al. 2020). Glycosyl hydrolase had been screened as immunogenic proteins in Clostridium chauvoei and identified as cell surface associated proteins by immunoproteomic method (Coral 2009). Phenyl alanyl-tRNA synthetase had been identified as immunogenic protein using immunoproteomic analysis of protective response obtained with subunit and commercial vaccine against glasser's disease caused by haemophilus parasuis ( $\mathrm{Li}$ et al. 2017). Immunogenic proteins which identified in different microorganism involved in different disease had also been explore in C. botulinum type B secretome these proteins may be used as vaccine candidate as well as diagnostic marker against the botulism. In this work, there were several highly plentiful proteins in the 2-DE gels which did not obtain as immunoreactive. Hence it is rational to recommend that the immunogenic proteins ones may be the noteworthy vaccine candidate as well diagnostic marker against botulism. The protective efficiencies of immunoreactive proteins identified either by alone or in altered combinations remain to be determined in further works.

\section{Conclusions}

The present study explored the secretome proteins of C. botulinum type B and identified the predominant immunogenic proteins using 2-DE immuno proteomic approach. To the best of our knowledge this is the first study to explore the secretome proteomics as well as identification of immuno dominant proteins of $C$. botulinum. In this study we have identified 17 immuno dominant in TPGY media and 10 proteins in CMM media. Five immunogenic proteins were common in both the media. Apart from that, cross reactive study of proteins had been also carried out to find out the cross reactive proteins in among $C$. botulinum types $\mathrm{A}, \mathrm{B}, \mathrm{E}$ and F. C. botulinum types A, B and E secretome showed the cross reactivity but $C$. botulinum type F did not show cross reactivity with the secretome of $C$. botulinum type B. Cross reactive proteins and common immunogenic proteins will be further validated in future study for their potential to be used as a vaccine/diagnostic candidates against infant and wound botulism.
Acknowledgments Ms. Arti Sharma thanks to Director DRDE Gwalior for the giving facility of practical work and UGC, New Delhi for the fellowship grant.

\section{Compliance with ethical standards}

Conflict of interest In the present work, authors had no conflict of interest.

\section{References}

Bernardini G, Braconi D, Lusini P, Santucci A (2007) Helicobacter pylori: immunoproteomics related to different pathologies. Expert Rev Proteomics 4:679-689. https:// doi.org/10.1586/14789450.4.5.679

Centers for Disease Control and Prevention (2011a) Notice of CDC's discontinuation of investigational pentavalent (ABCDE) botulinum toxoid vaccine for workers at risk for occupational exposure to botulinum toxins. MMWR Morb Mortal Wkly Rep 60:1454-1455

Chantada-Vázquez MdP, García-Vence M, Vázquez-Estévez S, Bravo SB, Núñez C (2020) Identification of a profile of neutrophil-derived granule proteins in the surface of gold nanoparticles after their interaction with human breast cancer sera. Nanomaterials 10:1223

Coral D (2009) Studies on novel immunogenic proteins of Clostridium Chauvoei.

Das PP, Lin Q, Wong S-M (2019) Comparative proteomics of tobacco mosaic virus-infected Nicotiana tabacum plants identified major host proteins involved in photosystems and plant defence. J Proteomics 194:191-199

Deatherage Kaiser BL, Hill KK, Smith TJ, Williamson CH, Keim P, Sahl JW, Wahl KL (2018) Proteomic analysis of four Clostridium botulinum strains identifies proteins that link biological responses to proteomic signatures. PLoS ONE 13:e0205586

Dwivedi P, Alam SI, Kumar O, Kumar RB (2015) Comparative analysis of extractable proteins from Clostridium perfringens type $\mathrm{A}$ and type $\mathrm{C}$ strains showing varying degree of virulence. Anaerobe 35:77-91

Forgber MTU, Sterry W, Walden P (2009) Proteome serological determination of tumor-associated antigens in melanoma. PLoS ONE 4:e5199

Forss N, Ramstad R, Backlund T, Lindstrom M, Kolho E (2012) Difficulties in diagnosing food-borne botulism. Case Rep Neurol 4:113-115. https://doi.org/10.1159/ 000339736000339736

Fulton KM, Twine SM (2013) Immunoproteomics: current technology and applications. Methods Mol Biol 1061:21-57. https://doi.org/10.1007/978-1-62703-589-7_ 2

Fulton KM, Baltat I, Twine SM (2019) Immunoproteomics methods and techniques. Springer, New York

Galvis AE (2019) Infant botulism in a 2-month-old female EC. Microbiology 15:227-229

He Z, Chen J, Ran X, Chen X, Bai Y, Xie X, Hou T (2013) Prokaryotic expression and immunogenicity analysis of 
phosphoglycerate kinase 1 of Candida albicans. Xi bao yu fen zi mian yi xue za zhi 29:1079-1081

Hirose I, Sano K, Shioda I, Kumano M, Nakamura K, Yamane K (2000) Proteome analysis of Bacillus subtilis extracellular proteins: a two-dimensional protein electrophoretic study. Microbiology 146(Pt 1):65-75

Jakhar R, Kumar P, Sehrawat N, Gakhar SK (2019) A comprehensive analysis of amino-peptidase N1 protein (APN) from Anopheles culicifacies for epitope design using Immuno-informatics models. Bioinformation 15:600

Kennedy PJ (2018) Targeting of human CD44v6 with engineered nanoparticles for gastrointestinal cancer diagnosis and therapy

Kim NY, Ahn HB, Yu CH, Song DH, Hur GH, Shin YK, Shin S (2019) Intradermal immunization with botulinum neurotoxin serotype E DNA vaccine induces humoral and cellular immunity and protects against lethal toxin challenge. Hum Vaccines Immunotherap 15:412-419

Kuehn B (2019) Wound botulism outbreak. JAMA 321:538-538

Lanci A et al (2019) The first case of botulism in a donkey. Vet Sci 6:43

Li G et al (2017) Identification of novel Haemophilus parasuis serovar 5 vaccine candidates using an immunoproteomic approach. J Proteomics 163:111-117

Liao X et al (2003) A two-dimensional proteome map of Shigella flexneri. Electrophoresis 24:2864-2882. https://doi. org/10.1002/elps.200305519

Lindstrom M, Keto R, Markkula A, Nevas M, Hielm S, Korkeala H (2001) Multiplex PCR assay for detection and identification of Clostridium botulinum types A B, E, and F in food and fecal material. Appl Environ Microbiol 67:5694-5699. https://doi.org/10.1128/AEM.67.12.56945699.2001

Ma C, Kojima K, Xu N, Mobley J, Zhou L, Yang ST, Liu XM (2015) Comparative proteomics analysis of high n-butanol producing metabolically engineered Clostridium tyrobutyricum. J Biotechnol 193:108-119

Maikanov B et al (2019) Clostridium botulinum and Clostridium perfringens occurrence in Kazakh honey samples. Toxins $11: 472$

Martinez-Gomez NC, Downs DM (2008) ThiC is an [Fe-S] cluster protein that requires AdoMet to generate the 4-amino-5-hydroxymethyl-2-methylpyrimidine moiety in thiamin synthesis. Biochemistry 47:9054-9056. https:// doi.org/10.1021/bi8010253

Martinez-Lopez RNC, Diez-Orejas R, Monteoliva L, Gil C (2008) Immunoproteomic analysis of the protective response obtained from vaccination with Candida albicans ecm33 cell wall mutant in mice. Proteomics 8:2651-2664

McClean RDAS (2012) Immunoproteomics: the key to discovery of new vaccine antigens against bacterial respiratory infections protein and peptide. Science 13:807-815

McManus DP (2020) Recent progress in the development of liver fluke and blood fluke vaccines. Vaccines 8:553

Mendum TANJ, McNeilly CL, McFadden J (2009) Towards the immunoproteome of Neisseria meningitidis. PLoS ONE 4:e5940

Merakou C, Schaefers MM, Priebe GP (2018) Progress toward the elusive Pseudomonas aeruginosa vaccine. Surg Infect 19:757-768
Monniot C, Zebre AC, Ake FM, Deutscher J, Milohanic E (2012) Novel listerial glycerol dehydrogenase- and phosphoenolpyruvate-dependent dihydroxyacetone kinase system connected to the pentose phosphate pathway. J Bacteriol 194:4972-4982

Nouwens ASWM, Walsh BJ, Cordwell SJ (2002) Proteomic comparison of membrane and extracellular proteins from invasive (PAO1) and cytotoxic(6206) strains of Pseudomonas aeruginosa. Proteomics 2:1325-1346

Palma NZ, da Cruz M, Fagundes V, Pires L (2019) Foodborne botulism: neglected diagnosis. Eur J Case Rep Internal Med 6:5

Pechine S, Hennequin C, Boursier C, Hoys S, Collignon A (2013) Immunization using GroEL decreases Clostridium difficile intestinal colonization. PLoS ONE 8:e81112

Pedersen SK et al (2005) An immunoproteomic approach for identification of clinical biomarkers for monitoring disease: application to cystic fibrosis. Mol Cell Proteomics 4:1052-1060

Pitarch ANC, Gil C (2011) Prediction of the clinical outcome in invasive candidiasis patients based on molecular fingerprints of five anti-Candida antibodies in serum. Mol Cell Proteomics 10(M110):004010

Pitarch AJA, Nombela C, Gil C (2006) Decoding serological response to Candida cell wall immunome into novel diagnostic, prognostic, and therapeutic candidates for systemic candidiasis by proteomic and bioinformatic analyses. Mol Cell Proteomics 5:79-96

Prasad TS et al (2013) Proteomic analysis of purified protein derivative of Mycobacterium tuberculosis. Clin Proteomics 10:8

Przedpelski A, Tepp WH, Zuverink M, Johnson EA, Pellet S, Barbieri JT (2018) Enhancing toxin-based vaccines against botulism. Vaccine 36:827-832

Sengupta N, Alam SI, Kumar B, Kumar RB, Gautam V, Kumar S, Singh L (2010) Comparative proteomic analysis of extracellular proteins of Clostridium perfringens type A and type $C$ strains. Infect Immun 78:3957-3968

Shah P, Atwood JA, Orlando R, El Mubarek H, Podila GK, Davis MR (2009) Comparative proteomic analysis of Botrytis cinerea secretome. J Proteome Res 8:1123-1130

Sharma A, Ponmariappan S, Sarita R, Alam SI, Kamboj DV, Shukla $S$ (2018) Identification of cross reactive antigens of C. botulinum types A B, E \& F by immunoproteomic approach. Curr Microbiol 75:531-540

Shimizu T, Shima K, Yoshino K, Yonezawa K, Hayashi H (2002) Proteome and transcriptome analysis of the virulence genes regulated by the VirR/VirS system in Clostridium perfringens. J Bacteriol 184:2587-2594

Siegrist MS, Swarts BM, Fox DM, Lim SA, Bertozzi CR (2015) Illumination of growth, division and secretion by metabolic labeling of the bacterial cell surface. FEMS Microbiol Rev 39:184-202

Sinha K, Bhatnagar R (2010) GroEL provides protection against Bacillus anthracis infection in BALB/c mice. Mol Immunol 48:264-271

Strauch KL, Carter TH, Miller CG (1983) Overproduction of Salmonella typhimurium peptidase T. J Bacteriol 156:743-751

Tsai-TienTseng BMTaJCS (2009) Protein secretion systems in bacterial-host associations, and their description in the 
gene ontology. BMC Microbiol. https://doi.org/10.1186/ 1471-2180-9-S1-S2

Vanitha Mariappan KMV, Vellasamy KM, Thimma JS, Hashim $\mathrm{OH}$, Vadivelu J (2009) Identification of immunogenic proteins from Burkholderia cepaciasecretome using proteomic analysis. Vaccine 28:1318-1324

Walz A et al (2007) Bacillus anthracis secretome time course under host-simulated conditions and identification of immunogenic proteins. Proteome Sci 5:11

Wang Y et al (2019) Comparative extracellular proteomics of Aeromonas hydrophila reveals iron-regulated secreted proteins as potential vaccine candidates. Front Immunol 10:256

Wang Y et al (2020) Identification and characterization of a Streptococcus suis immunogenic ornithine carbamoytransferase involved in bacterial adherence. J Microbiol Immunol Infect 53:234-239

Ys $\mathrm{S}$ et al (2004) Identification of antigenic proteins from Neospora caninum recognized by bovine immunoglobulins $\mathrm{M}$ E, A and $\mathrm{G}$ using immunoproteomics. Proteomics 4:3600-3609

Ziebandt AKW, Rudolph J, Schmid R, Hoper D, Engelmann S et al (2001) Extra-cellular proteins of Staphylococcus aureus and the role of SarA and sigma B. Proteomics $1: 480-493$

Publisher's Note Springer Nature remains neutral with regard to jurisdictional claims in published maps and institutional affiliations. 